\title{
Climatic Change Letters inaugural editorial
}

\author{
Stephen H. Schneider • Michael Oppenheimer
}

Received: 29 September 2009 / Accepted: 29 September 2009 / Published online: 21 October 2009

(C) Springer Science + Business Media B.V. 2009

With this issue, Climatic Change inaugurates a new section, Climatic Change Letters. Climatic Change Letters has a substantive scope that is similar to Climatic Change, but aims to provide a vehicle for rapid publication. Climatic Change is a journal of record for the research community that focuses on climatic variability and change from a range of disciplinary perspectives, with ample room for detailed presentation and discussion of implications. Climatic Change Letters publishes brief articles in the style of an announcement of new findings that would be of immediate and compelling interest to the same research and policy community. Submissions are limited to those where the necessary information may be presented within approximately four journal pages along with a modest amount of supplementary online material. Editorial decisions will be made in collaboration with members of the Climatic Change Letters Advisory Board (see http://www.springer.com/earth+sciences/ meteorology?SGWID=0-10009-12-565099-0 for a list of members of the advisory board and other details relevant to manuscript submission).

Letters aims to publish manuscripts online within about 3 months of submission followed by a hardcopy edition 1-2 months later. The first six articles were published online in a single batch, which led to slightly longer publication times for some of them. In the future, letters will appear online individually, as soon as the usual preparations have been completed. Hardcopy versions of Climatic Change will contain a Letters section every other month, composed of up to eight articles.

While this first batch of letters is simply the first six accepted and was not selected based on content, it does mirror the broad spectrum of research that has been the hallmark of Climatic Change, ranging from physical science of the climate system to

\footnotetext{
S. H. Schneider

Department of Biological Sciences, Stanford University, Yang \& Yamasaki Environment \& Energy Building, MC 4205, 473 Via Ortega, Stanford, CA 94305, USA

M. Oppenheimer $(\varangle)$

Department of Geosciences and Woodrow Wilson School of Public and International Affairs, Princeton University, Robertson Hall 448, Princeton, NJ 08544, USA

e-mail: omichael@princeton.edu
} 
the history of past changes inferred from interdisciplinary techniques, to impacts on humans and other species to the economics of societal responses and technologies for implementing climate policy. Noting that the articles by Richels et al., and Bosetti et al. were germane to the Copenhagen Conference of the Parties to the United Nations Framework Convention on Climate Change scheduled to convene on December 7, we invited economist Gary Yohe of Wesleyan University to provide an accompanying essay explaining the relevance of these findings in the policy arena.

We are extremely grateful to the community of climate experts for cooperating in the expedited review process that facilitates rapid publication. The volume and quality of manuscripts submitted since Letters opened its doors last spring substantiates the need that we anticipated, and we hope that the community is willing to continue to contribute its time and wisdom to the review process if, as we hope and expect, the flow of submissions continues to increase. We also thank the Letters advisory board for their quick and insightful evaluations of submissions.

Finally, we hope the entire community will consider Letters as a vehicle for rapid dissemination of new ideas, new approaches, and new findings, while at the same time availing itself of the capaciousness of Climatic Change for full exposition of such research, and its implications for society. 